\title{
Comparative Analysis of Leaf Vein Density in Sri Lankan Traditional Rice Varieties
}

\author{
I.K. Edirisingha, E.M.T.P. Ekanayaka ${ }^{1}$, D.V. Jayatilake² and H.M.V.G. Herath2,3* \\ Postgraduate Institute of Agriculture \\ University of Peradeniya \\ Sri Lanka
}

\begin{abstract}
The C3 photosynthetic pathway of rice is less efficient than the C4 pathway. The possibility of conversion from $\mathrm{C} 3$ to $C 4$ pathways in rice is currently under experiment. In plants undergoing such a transition, higher leaf-vein densities (LVD), and development of Kranz anatomy is expected to be present at an initial stage. High LVD could exist among traditional rice and those could be used as a starting point towards developing $C 4$ rice. In the present study, LVD (estimated by average vein length between, two large longitudinal veins $(L L V)$, two small longitudinal veins (SLV), and the vein length per unit area (TLV)) of 23 Sri Lankan rice accessions were analysed by performing a one-way ANOVA, with mean separation using Duncan's multiple range test. Among the tested varieties LLV, SLV, and TLV were found to be significantly $(p<0.05)$ different among accessions. Based on the mean separation, the highest LLV was shown by Thanthiribalan, and the lowest by Dewareddhiri, Mahasuduwee, Suwadel and five other accessions. The highest SLV was reported in three accessions and the lowest was in Mahasuduwee, Suwadel and Mahakuruwee. The highest TLV was reported in Mahasuduwee, Suwadel and Mahakuruwee and the lowest in IR 64. Unlike $T L V$ estimation, SLV can be measured directly. Given that TLV and SLV are negatively correlated ( $r=-0.9183)$ a low SLV will be a suitable parameter to select for high TLV. The accessions, Mahasuduwee, Suwadel and Mahakuruwee carried a higher LVD (lower SLV and $L L V$ leading to higher TLV) and can be recommended as candidates for studying C3 to C4 photosynthetic pathway conversion in rice.
\end{abstract}

Keywords: C3/C4 rice; Kranz anatomy; Leaf anatomy; Leaf vein density

\section{INTRODUCTION}

Rice (Oryza sativa L.), is a cereal crop that fulfils the main caloric requirement of over half of the world's population (Bhat et al., 2018). As we step into the year 2050, the world population is predicted to be 9.7 billion, a $34 \%$ increase compared to today's population. With population growth, the demand for rice is expected to be doubled by 2050 (FAO, 2009). To meet this demand, rice yield needs to be increased significantly. Even though in the recent past the rice yield increased due to precise breeding techniques leading to the development of high yielding varieties and hybrids, currently, the rice yield has come to a plateau (Godfray et al., 2010). The unpredictable climate is one of the challenges faced by the farmers and plant breeders in

\footnotetext{
${ }^{1}$ Chungnam National University, Daejeon, Republic of Korea

${ }^{2}$ Department of Agricultural Biology, Faculty of Agriculture, University of Peradeniya, Peradeniya, Sri Lanka

3 Texas A\&M Institute for Plant Genomics and Biotechnology, 498 Olsen Blvd., College Station, TX, USA

* Corresponding author: venurah@pdn.ac.lk
} 
today's agriculture. Climate change drastically affects the rice yield and hence, farmers struggle to obtain a good harvest under the constantly changing climatic conditions. Development of rice varieties that can produce better yields under adverse and erratic climatic conditions is therefore a current necessity.

The evolutionary trends of photosynthetic pathways have revealed that $\mathrm{C}_{4}$ plants evolved from $\mathrm{C}_{3}$ plants as an adaptation for high temperature and low $\mathrm{CO}_{2}$ in the atmosphere (Christin et al., 2008). In doing so, the $\mathrm{C}_{4}$ plants have adapted a unique tissue arrangement with bundle sheath cells and mesophyll cells, referred to as "Kranz anatomy"; an arrangement of two concentric rings of cells, inner bundle sheath cells containing most of the chloroplasts, encapsulated in a layer of mesophyll cells (Nelson, 2011; Lundgren et al., 2014). For the efficient function of the $\mathrm{C}_{4}$ pathway, close contact and interaction between mesophyll and bundle sheath cells are important. When the two cell types are in close proximity, where each and every mesophyll cell is directly adjacent to at least one bundle sheath cell, interconnected via plasmodesmata, $\mathrm{CO}_{2}$ get more efficiently accumulated in the bundle sheath cells (Dengler and Nelson, 1998). The Kranz anatomy and $\mathrm{C}_{4}$ photosynthetic pathway lead to minimizing the photorespiration through compartmentalization and improves the efficiency of photosynthesis by minimizing the energy wastage. Of the cereals cultivated in the world, rice, wheat, and barley follow the $\mathrm{C}_{3}$ photosynthetic pathway, and maize, sorghum, millet, and sugarcane, the $\mathrm{C}_{4}$ photosynthetic pathway. As reviewed by Sage et al. (2011), higher plant lineages of $\mathrm{C}_{3}-\mathrm{C}_{4}$ intermediate photosynthesis is reported in several grass families, however, not in any of the crop species.

The $\mathrm{C}_{4}$ pathway is characterized by high vein density (Gowik and Westhoff, 2011). Differentiation of bundle sheath cells and their localization is regulated through hormones (such as auxin, and cytokinin), brassinosteroids, small RNAs, peptides, transcription factors, and metabolites elicited by the leaf vascular centres (Nelson, 2011). Formation of veins, number or pattern of veins depends on the polar auxin transportation inside the newly developing leaf tissues (Sachs, 1991). Further, the vein development depends on the paths link to the auxin transport for the sinks and sources (Berleth et al., 2000). Auxin and its transportation pathways induce differentiation of mesophyll and bundle sheath cells to avoid the lateral spreading of auxin (Sachs, 1991; Berleth and Mattsson, 2000). Auxin transport pathways are regulated by small RNAs and a collection of transcription factors produce from the vascular centre (Lyer-Pascuzzi and Benfey, 2000).

Therefore, the high leaf vein density in plants is considered as a developmental indicator of an efficient photosynthetic pathway. In order to capture the desirable attributes of the $\mathrm{C}_{4}$ plants that make them climate-ready, the International Rice Research Institute in Philippines is hosting a consortium to develop a " $\mathrm{C}_{4}$ rice variety" through $\mathrm{C}_{4}$ engineering (http://photosynthome.irri.org/c4j3/\#). Even though $\mathrm{C}_{4}$ engineering has met its fair share of challenges, the approach could lead to the next revolution in crop production (Von et al., 2012) The vein network of the leaf comprises of small longitudinal veins (SLV) and large longitudinal veins (LLV), interconnected via transverse veins. These collectively translocate the photosynthetic products assimilated from surrounding cells out of the leaf in to the phloem (McKown and Dengler, 2009). Most of the environmental factors (e.g. $\mathrm{CO}_{2}$ concentration in atmosphere) did not change the leaf vein density of plants, therefore it is identified as a heritable trait (Uhl and Mosbrugger, 1998). Given that high leaf vein density (LVD) is identified as an evolutionary important trait in $\mathrm{C}_{3}$ to $\mathrm{C}_{4}$ conversion, mutation breeding attempts were made to develop lines with higher LVD (Feldman et al., 2014). However, there could be naturally occurring accessions with higher LVD. In the current study, the LVD of several Sri Lankan rice accessions was assessed to select germplasm with potentially higher LVD to perform further analysis on their suitability as a model for studying $\mathrm{C}_{3}$ to $\mathrm{C}_{4}$ conversion. 


\section{METHODOLOGY}

\section{Rice Materials}

In the current study, IR 64 and 23 Sri Lankan rice accessions sourced from the Plant Genetic Resource Centre, Gannoruwa, Sri Lanka were used for assessing the LVD (Dewareddhiri (4610), Kallundai samba (3381), Kotathavalu (3659), Madayal vee (3269), Moroberekan (6897), Norunkan (3241), Pachchaperumal (3136), Pokkali (3251), Rathu heeneti (4992), Sivappu kuruvikkar (4868), Sudu heeneti (2088), Thavalu (3634), IR-64 (9483), Wannidahanala (2053), Batapolael (2105), Podihatatha (3174), Yakada wee (3445), Halsuduwee (3877), Kottiyaran (4630), Suwadel (4802), Herath banda (2063), Thanthiribalan (3072), Mahakuruwee (3190), and Mahasuduwee (3662)). The study was conducted at the Department of Agricultural Biology, Faculty of Agriculture, University of Peradeniya during the period 2016 to 2017.

\section{Planting and Experimental Design}

The seeds were germinated in Petri-dishes and two-weeks old seedlings were transplanted in pots in 6 replicates according to a completely randomized design. The second week after germination, nutrients were applied through half strength Yoshida solution (Cock et al., 1976) and was switched to full strength Yoshida solution at two-weeks after transplanting. Urea was applied according to the recommendation of the Department of Agriculture in the fourth week and sixth week after transplanting.

\section{Data Collection}

For the LVD calculation, a one-centimetre leaf sample was collected from the widest middle portion of the first leaf (the leaf directly below the flag leaf) of the main culm of each rice plant from each species separately (Ueno et al., 2006). Permanent slides were prepared by mounting the leaf sections on $70 \%$ glycerol. The slides were observed under a $20 \times$ magnification and imaged using a microscope eye-piece camera (AM7013MT Dino-light and Dino eye, AnMo Electronic Corporation, Torrance, California, USA). The average vein length between two LLV and two SLV, and the vein length per unit area (TLV) were calculated based on an image analysis conducted using software Dino-Capture 2.0 v1.5.18.A (European distributers, Europe).

\section{Data Analysis}

In all 24 varieties LLV, SLV and TLV were statistically analysed using a one-way ANOVA with PROC GLM function, and mean separation was carried out using Duncan's multiple range test. The correlation between LLV, SLV and TLV were assessed using SAS v9.1.3 (SAS Institute Inc., Cary, NC, USA).

\section{RESULTS AND DISCUSSION}

The plants with a $\mathrm{C}_{4}$ photosynthetic pathway are more efficient in assimilating carbon compared to those with a $\mathrm{C}_{3}$ photosynthetic pathway. While in most plants the leaf anatomy is reflective of the photosynthetic pathway that it adopts (i.e. $\mathrm{C}_{3}$ or $\mathrm{C}_{4}$ ), there are plants with anatomy that is in the transition from that of $C_{3}$ to $C_{4}$. The evolution of $C_{3}$ to $C_{4}$ is said to be governed by the development of leaf anatomy with a high LVD, a characteristic of $\mathrm{C}_{4}$ plants 
(Feldman et al., 2014). The LVD impacts the photosynthetic efficiency by influencing the development of Kranz anatomy and by increasing the bundle sheath to mesophyll cell ratio through hormonal and transcriptional regulation. It also increases the translocation of photosynthates for phloem loading. So high LVD in a rice plant indicates prospects towards engineering a rice plant with better photosynthetic capacity.

Sri Lankan rice germplasm is a diverse genetic resource which may harbour accessions with higher LVD. Such accessions could be ideal candidates to initiate further research towards engineering a rice plant with high photosynthetic capacity. According to Ueno et al. (2006), rice plants with high LVD has shown a reduction of the length between LLV, and an increase in the length between SLV and the TLV. In the current study, 23 Sri Lankan rice accessions were analyzed considering, mean length of the LLV, SLV and TLV as indicator parameters to select accessions with high LVD. The variety IR 64 was used as a reference accession, given that most of the earlier studies on vein density analysis in rice were conducted using mutant populations derived from a single IR 64 plant produced at IRRI.

The LLV length is inversely related to the LVD. Among the rice accessions evaluated in the current study, the highest LLV was shown by Thanthiribalan, however, the accession is not significantly different $(p \geq 0.05)$ to Herath Banda, IR 64, and Moroberekan. The lowest LLV was reported by Dewareddhiri (Figure 1), while it was not significantly different $(p \geq 0.05)$ from LLVs of Suwadel, Mahasuduwee, Yakadawee, Kottiyaran, Kotathawalu, Pokkali, Madayal wee, Batapolael, Kallundai samba, and Norunkan. The highest and lowest LLV groups were significantly $(p \leq 0.05)$ different from each other.

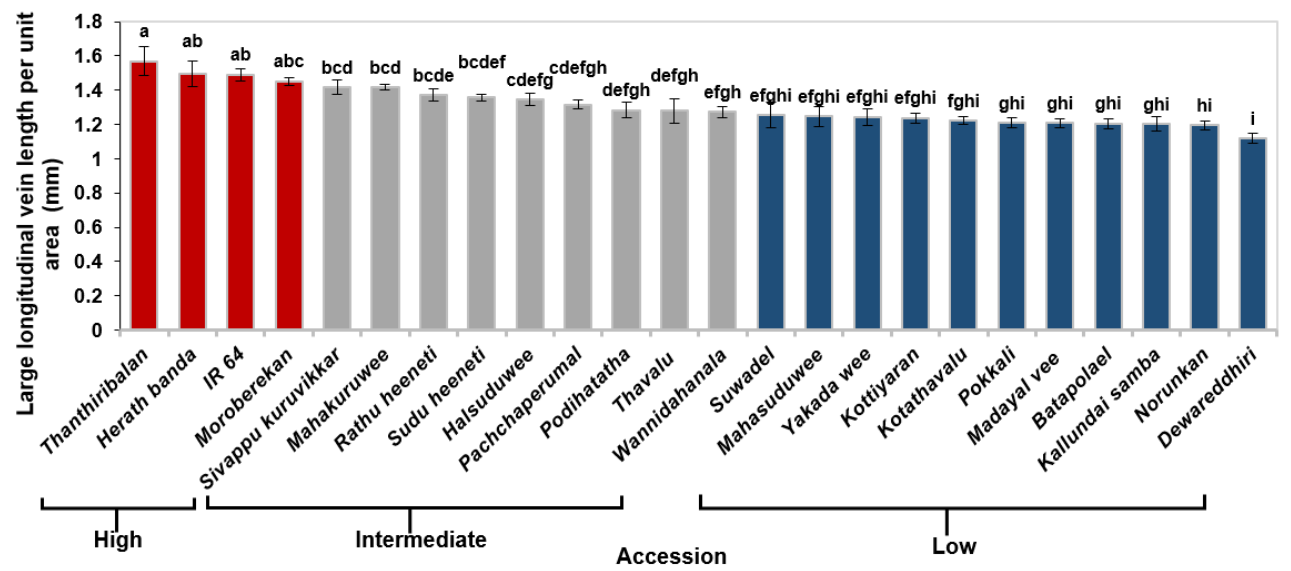

Figure 1. The variation of the mean length of the large longitudinal veins (LLV) of the $7^{\text {th }}$ leaf of the selected 24 rice accessions.Values with the same letter (a-i) are not significantly different $(p \geq 0.05)$. Error bars indicate the standard error.

The SLV also has an inverse relationship with leaf vein density (Figure 4). The highest SLV was shown by Pachchaperumal, Sivappu kuruvikkar and Moroberekan. However, the accessions Wannidahanala, Suduheenati and IR64 were not significantly $(p \geq 0.05)$ different from the highest SLV group. The lowest SLV was reported in Mahasuduwee, however, it was not significantly different from SLV of 
Suwadel and Mahakuruwee (Figure 2). The highest and lowest SLV groups were significantly $(p \leq 0.05)$ different from each other.

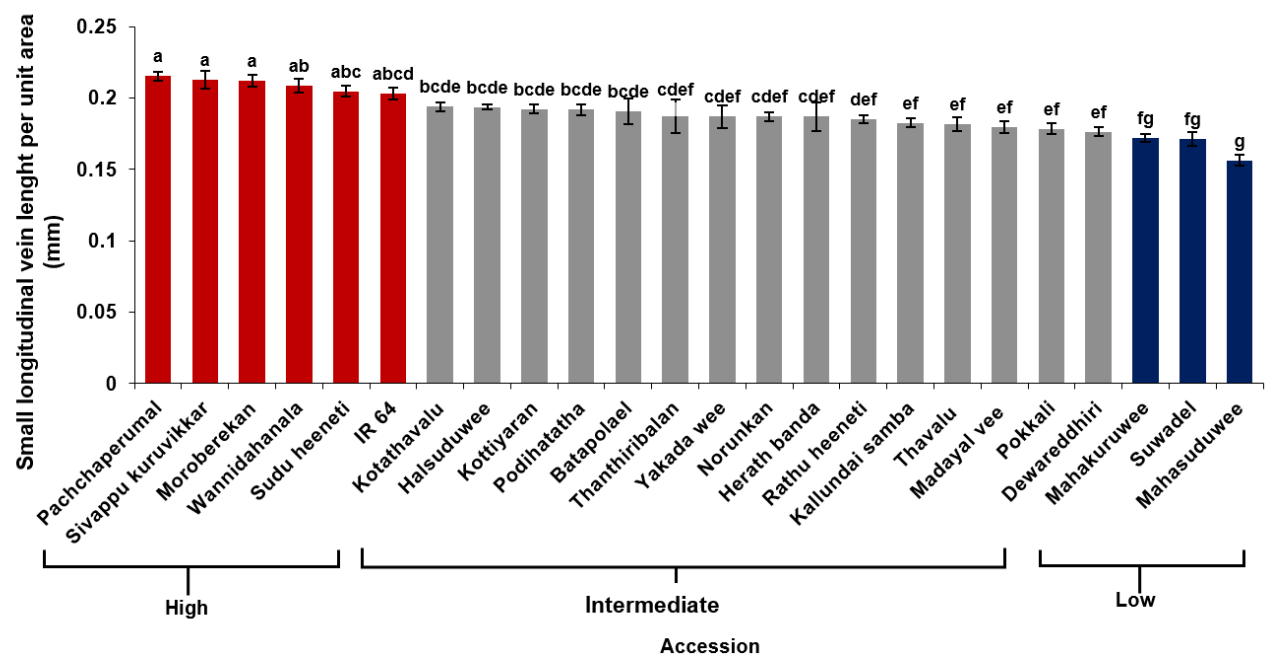

Figure 2. The variations of the mean length of the small longitudinal veins (SLV) of the $7^{\text {th }}$ leaf of the selected 24 rice accessions. Values with the same letter (a-g) are not significantly different $(p<0.05)$. Values are given as \pm standard error.

The lowest mean LLV and SLV lengths are important for the increasing number of LLV and SLV in a unit area of the rice leaf, hence, indicates a higher LVD (Ueno et al., 2006). According to the result, Mahasuduwee, Suwadel and Mahakuruwee are identified as rice accession with lowest SLV. Dewareddhiri showed the lowest SLV in the intermediate group (Figure 2). Further, Mahasuduwee and Suwadel were identified as having lowest LLV along with Dewareddhiri and five other accessions (Figure 1). Therefore, these three traditional accessions could be considered as rice accessions carrying higher LVD based on LLV and SLV.

The TLV variation of the 24 accessions ranging from 4.5 to $7.0 \mathrm{~mm} / \mathrm{mm}^{2}$ is shown in Figure 3. The highest TLV was in the accessions Mahasuduwee and it is $6.7 \mathrm{~mm} / \mathrm{mm}^{2}$. The accessions Suwadel, Mahakuruwee, Thanthiribalan, Dewareddhiri and Madayal vee were significantly $(p \leq 0.05)$ different from Mahasuduwee, however, was included in the second highest TLV group (Figure 3). The higher TLV indicates high LVD. So, accessions Mahasuduwee, Suwadel and the Mahakuruwee can be considered as potential high LVD candidates.

The correlation between SLV, LLV and TLV analysis is important to know the relationship between above-mentioned leaf parameters. According to the Pearson's correlation analysis, the correlation between SLV and LLV is positive, and the correlation between TLV and LLV is negative. Further, the correlation between TLV and SLV is strongly negative ( $r=-0.9$; Figure 4). Therefore, low SLV can be used as 
an indicator of high TLV, and hence can be used as an indirect measurement instead of calculating the TLV.

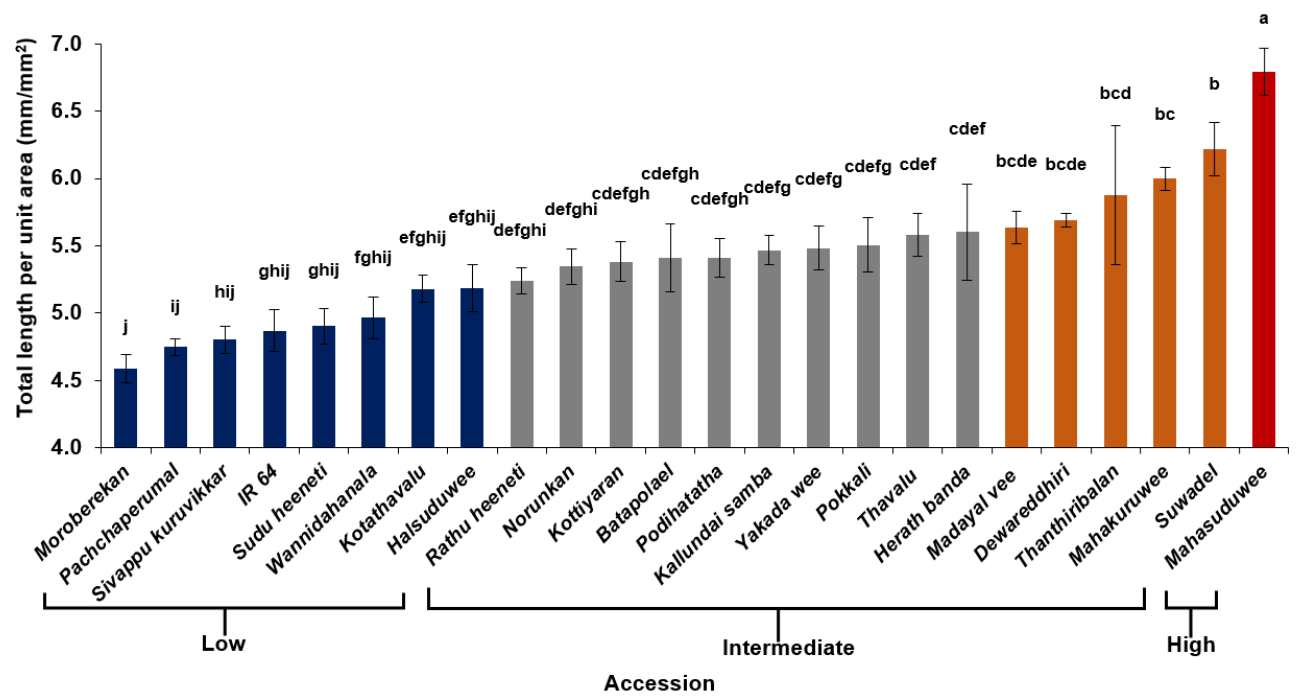

Figure 3. The variations of the total length per unit area (TLV) of the $7^{\text {th }}$ leaf of the selected 24 rice accessions. Values with the same letter (a-j) are not significantly different $(p<0.05)$. Values are given as \pm standard error.

Based on the SLV, LLV and TLV analysis, the lowest SLV and LLV, as well as highest TLV, were shown in accessions Mahasuduwee, Suwadel and Mahakuruwee.

\begin{tabular}{|c|c|c|c|}
\hline LLV & 1 & & \\
\hline SLV & 0.2712 & 1 & \\
\hline \multirow[t]{2}{*}{ TLV } & -0.1221 & -0.9183 & 1 \\
\hline & LLV & SLV & TLV \\
\hline
\end{tabular}

Figure 4. Correlation analysis heat map for large longitudinal vein (LLV) length, small longitudinal vein (SLV) length, and the vein length per unit area (TLV). Each value represents the Pearson correlation coefficient $(r)$ at $p<0.05$ between each measurement. Positive values represent positive correlation and the negative values represent the negative correlation. 
As reviewed by Karki et al. (2013) by introducing $\mathrm{C}_{4}$ photosynthetic pathway in to $\mathrm{C}_{3}$ photosynthetic plants the nitrogen use efficiency can be enhanced and the water losses can be reduced, leading to a yield increase. The initial step towards genetically engineering a rice plant with high photosynthetic capacity begins with increasing the leaf vein density. Therefore, the identification of rice accessions carrying high leaf vein densities in the current study will benefit the $\mathrm{C}_{4}$ rice consortium efforts as well as studies that focus on understanding the anatomy and physiology of vein development in rice.

\section{CONCLUSIONS}

The parameters SLV and TLV showed a significant negative correlation, and therefore, low SLV can be used as an estimate of a high TLV. Among the tested 24 accessions the highest LLV was shown by Thanthiribalan, and the lowest was shown by Dewareddhiri, Mahasuduwee, Suwadel and eight another accessions such as Yakadawee, Kottiyaran, Kotathavalu, Pokkali, Madayal vee, Batapolael, Kallundai samba, Norunkan. The highest SLV was reported in the accessions Pachchaperumal, Sivappu kuruvikkar, and Moraberakan along with another three accessions such as Wannidahanala, Suduheeneti, IR64 and the lowest was represented in three accessions Mahasuduwee, Suwadel and Mahakuruwee. The highest TLV was reported in Mahasuduwee, Suwadel and Mahakuruwee and the lowest in IR 64. Therefore, Mahasuduwee, Suwadel and Mahakuruwee carried the highest LVD, and they can be recommended as potential accessions for studying the $\mathrm{C}_{3}$ to $\mathrm{C}_{4}$ photosynthetic pathway conversion in rice.

\section{ACKNOWLEDGEMENTS}

The authors wish to acknowledge the funding from the National Research Council of Sri Lanka (NRC/14/117), Prof. K.S. Hemachandra of the Department of Agricultural Biology, Faculty of Agriculture, University of Peradeniya for facilitating the use of microscope eye-piece camera and the Plant Genetic Resource Centre, Gannoruwa, Sri Lanka for providing the seeds of the 24 rice accessions.

\section{REFERENCES}

Berleth, T. Mattsson, J. (2000) Vascular development: tracing signals along veins. Curr. Opin. Plant. Biol. 3, pp. 406-411.

Berleth, T. Mattsson, J. Christian S. H. (2000) Vascular continuity and auxin signals. Trends Plant Sci. 5(9), 387-393.

Bhat, R. Singh, A. K. Salgotra, R. K. Sharma, M. Bagati, S. Hangloo, S. Bhat, M. I. . Sharma, S.K. Mushtaq, M. (2018) Statistical description, genetic variability, 
heritability and genetic advance assessment for various agronomical traits in $\mathrm{F}_{2}$ population of rice (Oryza sativa L.). J. Pharmacogn Phytochem. 7(3), 985-992.

Christin, P. A. Besnard, G. Samaritani, E. Duvall, M. R. Hodkinson, T. R. Savolainen, V. Salamin, N. (2008) Oligocene $\mathrm{CO}_{2}$ decline promoted $\mathrm{C}_{4}$ photosynthesis in grasses. Curr. Plant. Biol. 18(1), 37-43.

Cock, J. Yoshida, S. Forno, D. A. (1976) Laboratory manual for physiological studies of rice. Int. Rice Res. Inst.

Dengler, N. G. Nelson, T. (1998) Development in $\mathrm{C}_{4}$ Plants. $\mathrm{C}_{4}$ plant biology. Elsevier. pp. 133.

FAO (2009). How to feed the world in 2050. Insights from an expert meeting at FAO 2050. pp. 1-35.

Feldman, A. B. Murchie, E. H. Leung, H. Baraoidan, M. Coe, R. Yu, S. M. Lo, S. F. Quick, W. P. (2014) Increasing leaf vein density by mutagenesis: Laying the foundations for $\mathrm{C}_{4}$ rice. PLoS One. 9(4), e94947.

Godfray, H. C. J. John, R. Beddington, Ian, R. Crute, Lawrence Haddad, David, L. James, F. Muir, Jules, P. Sherman, R. Sandy, M. Thomas, Camilla, T. (2010) Food Security: The Challenge of Feeding 9 Billion People. Science. 327, 812-818.

Gowik, U. Westhoff, P. (2011) The path from $\mathrm{C}_{3}$ to $\mathrm{C}_{4}$ photosynthesis. Plant Biochem. Physiol. 155(1), 56-63.

Iyer-Pascuzzi, A. S. Benfey, P. N. (2009) Transcriptional networks in root cell fate specification. Biochim. Biophys. Acta. 1789(4), 315-325.

Karki, S. Rizal, G .Quick, W. P. (2013) Improvement of photosynthesis in rice (Oryza sativa $\mathrm{L}$.) by inserting the $\mathrm{C}_{4}$ pathway. Rice. 6,28 .

Kropff, M. J. Cassan, K. G. Penning, De Vries, F. W. T. Van Laar, H. H. (1993) Increasing the yield plateau in rice and the role of global climate change. J. Agr. Met. 48(5), 795-798.

Lundgren, M. R. Osborne, C. P. Christin, P. A. (2014) Deconstructing Kranz anatomy to understand $\mathrm{C}_{4}$ evolution. Journal of Experimental Botany. 65(13), 3357-3369.

McKown, A. D. Dengle, N. G. (2009) Shifts in leaf vein density through accelerated vein formation in $\mathrm{C}_{4}$ Flaveria (Asteraceae). Ann. Bot. 104(6), 1085-1098.

Nelson, T. (2011) The grass leaf developmental gradient as a platform for a systems understanding of the anatomical specialization of $\mathrm{C}_{4}$ leaves. J. Exp. Bot. 62(9), 3039-3048.

Sachs, T. (1991) Cell polarity and tissue patterning in plants. Dev. Suppl. 1, 83-93. 
Sage, R. F. Christin, P. A. Edwards, E. J. (2011) The $\mathrm{C}_{4}$ plant lineages of planet Earth: Journal of Experimental Botany. Oxford University Press. 62(9): pp. 3155-3169.

Ueno, O. Kawano, Y. Wakayama, M. Takeda, T. (2006) Leaf vascular systems in $\mathrm{C}_{3}$ and $\mathrm{C}_{4}$ grasses: A two-dimensional analysis. Ann. Bot. 97(4), 611-621.

Uhl, D. Mosbrugger, V. (1998) Leaf venation density as a climate and environmental proxy: a critical review and new data. Palaeo. 149, 15-26.

Von, C.S. Quick, W. P. Furbank, R. T. (2012) The development of $\mathrm{C}_{4}$ rice: current progress and future challenges, science. Sci. Adv. 336(6089), 1671-1672. 